\title{
Marketing Strategy for Unusual Brand Differentiation: Trivial Attribute Effect
}

\author{
M. Deniz Dalman ${ }^{1} \&$ Junhong Min ${ }^{2}$ \\ ${ }^{1}$ Marketing and Branding Consultant at Dogruluk International Transportation Co. and Ozdogruluk Custom \\ Clearance Co., Istanbul, Turkey \\ ${ }^{2}$ School of Business and Economics, Michigan Technological University, Michigan, USA \\ Correspondence: M. Deniz Dalman, Ozdogruluk Custom Clearance Co., Mumhane Cd. No: 41/2, Karakoy, \\ Istanbul, Turkey. Tel: 90-532-325-3575. E-mail: denizdalman@gmail.com
}

Received: June 22, 2014 Accepted: July 11, 2014 Online Published: September 28, 2014

doi:10.5539/ijms.v6n5p63 URL: http://dx.doi.org/10.5539/ijms.v6n5p63

\begin{abstract}
This research investigates that brand differentiation creating superior values can be achieved not only by adding meaningful attributes but also meaningless attributes, which is called "trivial attribute effect." Two studies provided empirical evidences as following; first, trivial attribute effect creates a strong brand differentiation even after subjects realize that trivial attribute has no value. Second, trivial attribute effect is more pronounced in hedonic service category compared to the utilitarian category. Last, the amount of willingness to pay is higher when trivial attribute is presented and evaluated in joint evaluation mode than separate evaluation mode. Finally, we conclude with discussion and provide suggestions for further research.
\end{abstract}

Keywords: brand differentiation, evaluation mode, service industry, trivial attribute

\section{Introduction}

\subsection{Problem Definition}

Perhaps the most important factor for new product success is to create the meaningful brand differentiation that provides customers with superior values beyond what the competitors can offer in the same industry (Porter, 1985). Not surprisingly, more than 50 percent of annual sales in consumer product industries including automobiles, biotechnology, computer software, and pharmaceuticals are attributed to such meaningful brand differentiation by including new or noble attributes (Schilling \& Hill, 1998). However, the brand differentiation that increases consumer preference is not only by introducing meaningful attributes but also meaningless attributes. For example, it is not unusual to see brands differentiating themselves in the marketplace by adding some non-important attributes to their offerings (e.g., Coca-Cola's "S" shape bottle, Pantene shampoo with vitamins or Folgers coffee changing the shape of coffee particles). These non-important or trivial attributes as the marketing literature suggests are attributes that "appears valuable but, on closer examination, is irrelevant or trivial to creating the implied benefit" (Carpenter, Glazer, \& Nakamoto, 1994, p. 339).

In marketing, the successful brand differentiation by trivial attributes has been discussed and explained by three different research streams. First, research on trivial attributes has shown that offering these attributes increase brands' buying likelihood by giving consumers reasons or rational for choice (Brown \& Carpenter, 2000). Interestingly, even after consumers realized that the brand differentiation by trivial attribute didn't create any meaningful differentiation, their brand choice was the same (Carpenter et al., 1994). Second, Miljkovic, Gong, and Lehrke (2009) find that this trivial attribute effect on brand differentiation depends on the choice set. Specifically, they find that when the choice set consists of at least three brands-where each brand is strong on certain attributes and it is difficult for consumers to make a choice, offering a trivial attribute serves as a "tie-breaker" and thus increases the buying likelihood of that brand. Last, literature reveals that brand differentiation can be obtained by how competing brands are presented and evaluated either separately or jointly which is called the "evaluation mode effect." Hsee, Loewenstein, Blount, and Bazerman (1999) introduce the two types of evaluation modes: separate evaluation and joint evaluation. Separate evaluation describes the evaluation context in which brands are evaluated one at a time. Joint evaluation means that the brands are evaluated simultaneously. In particular, joint evaluation increases transparency when competing brands are 
evaluated (Chatterjee, Heath, \& Min, 2009). Thus, when a brand with trivial attribute is presented and evaluated jointly with another brand without trivial attribute, consumers are easy to identify uniqueness of the brand with trivial attribute, which results in brand differentiation and brand preference. Studies in the evaluation mode literature continue to provide strong empirical evidences that the evaluation mode effect is particularly strong when consumers need to evaluate brands with uncertainty (Chatterjee et al., 2009; Hsee et al., 1999).

\subsection{The Purpose of This Research}

Although our knowledge of trivial attribute effect has been greatly enhanced, how the trivial attribute affects brand evaluation has never been studied from the perspective of product development and marketing strategy. Our research aims to fill the gap by offering empirical evidences from two studies. The goals of this paper is fourth folds; 1) Can brands increase their choice likelihood by adding some trivial attributes, 2) Does this effect depend on the nature of the category (i.e. hedonic vs. utilitarian), 3) Does the type of trivial attributes (hedonic vs. utilitarian) affect the consumer response to these trivial attributes, and finally 4) How can marketing managers effectively communicate a brand with trivial attribute? To reach these goals, in the first study, we review trivial attribute effect, and test how it creates the brand differentiation in service sector. Then, in the second study, we discuss about the evaluation mode literature, and test that the effect whether trivial attribute is more salient in joint evaluation or separate evaluation mode. Finally, we conclude with discussion and provide suggestions for further research.

\section{Theoretical Background}

\subsection{Trivial Attribute Effect on Service Choice}

Trivial attributes are defined as the attributes that do not create meaningful differentiation in evaluation of alternatives (Broniarczyk \& Gershoff, 2003; Miljkovic et al., 2009). Consumers treat this trivial information in the advantage of brands that offer them even when they are informed before decision-making about the triviality (Carpenter et al., 1994). Brown and Carpenter (2000) explain this advantage with the reasons based account. They argue that consumers prefer to choose on the basis of easily justified, cognitively available reasons (Brown $\&$ Carpenter, 2000). Thus, when the options cannot be chosen based on important attributes, consumers need to rely on trivial attributes that create brand differentiation (Shafir, Simonson, \& Tversky, 1993).

The question about what to add to the offering to increase its value is especially important for services (Devlin, 1998), as it is more difficult to create a competitive advantage in service industries (Storey \& Easingwood, 1998). The main reason is that unlike physical goods, services are intangible and consumers often face a problem of identifying the necessary attributes in services for evaluation. Thus, they end up only relying on brand comparisons on the basis of selected attributes (Gabott \& Hogg, 1994; Rust \& Chung, 2006). Therefore, services create more uncertainty for consumers than physical goods at the purchase stage. When a decision can't be justified on relevant attributes, consumers form arguments based on trivial attributes even after they are told about the triviality of the attribute (Albrecht, Neumann, Haber, \& Bauer, 2011). Therefore, with the amount of uncertainty in services and the difficulty of evaluating attributes as mentioned above, consumers are likely to use trivial attributes when they are faced with an ambiguous choice set even after they are told about the triviality. We posit the hypothesis as follows;

\section{H1: The choice likelihood of service provider that offers a trivial attribute will be higher than that does not offer.}

Compared to physical goods, services are based on information processing (Rust \& Chung, 2006) and how the information is processed depends on whether the service is utilitarian or hedonic (Hirschman \& Holbrook, 1982). According to Batra and Ahtola (1991), consumers have these two motives in a choice context. Hedonic services are related to "fun" and "pleasure" (Babin, Darden, \& Griffin, 1994) whereas utilitarian services are related to "functionality" (Strahilevitz \& Myers, 1998). In a choice context, the outcomes of these two types of services are valued differently as the utilitarian outcome depends on objective standards whereas hedonic ones depend on subjective (discretionary) standards (Botti \& McGill, 2010). Moreover, Botti and McGill (2010) argue that hedonic motives are sought "as an end itself" whereas utilitarian motives are used to reach a higher-level goal. We argue that utilitarian services are more anxiety provoking than hedonic services as they include important, harder to achieve, and uncertain goals (Lazarus, 1991). And in situations, when goals are anxiety provoking, trivial attributes are more influential (Xiao, Dacin, \& Ashworth, 2011). Therefore, we expect the effect of trivial attributes to be more pronounced in a hedonic service category than in a utilitarian service category. We posit the hypothesis as follows:

H2: The advantage of service provider that offers a trivial attribute will be more pronounced for the hedonic services compared to utilitarian services. 


\subsection{Marketing Communication Strategy Using Trivial Attribute Effect}

Prior literature has suggested that comparison is a natural and powerful strategy that consumers often rely on (Cooke, Janiszewski, Cunha Jr, Nasco, \& De Wilde, 2004; Dhar, Nowlis, \& Sherman, 1999). Hsee and Leclerc (1998) suggest that consumer preference changes depending on how products are presented and evaluated, specifically, whether they are evaluated separately (separate evaluation mode) or jointly (joint evaluation mode). For example, in separate evaluation when one is asked to rate the importance of supporting government intervention for saving dolphins over preventing skin cancer among farm works, the number of people who supports the government intervention for saving dolphins is substantial. However, in the joint evaluation mode when the same person is asked to compare the importance of dolphin to that of a human side by side (or jointly) the majority of people's answer is obvious to support a human.

Thus, consumers in joint evaluation mode not only greatly save their efforts but also increase accuracy in choice because it is easier to identify similarities and differences between competing brands. This evaluation strategy focusing on the difference or something unique makes the trivial attribute become salient and even meaningful (Dhar\& Sherman, 1996). Taken together, we posit that brand with trivial attribute will be perceived more valuable (i.e., people are willing to pay more) in the joint evaluation mode than it is in the separate evaluation mode.

\section{H3: Willingness to Pay (WTP) is higher in the joint evaluation mode than that in the separate evaluation mode.}

\section{Method}

\subsection{Study1: Trivial Attribute Effect}

\subsubsection{Manipulations and Procedure}

We employed a mixed design experiment with the participation of eighty-four undergraduate students from a marketing class. Subjects were given a scenario to simulate a decision stage among three different service providers. The design was 3 (Service Providers) X 2 (Service Category) X 3 (Trivial Attributes) with the service providers being a within-subject factor and the latter two between-subject factors. Service category includes a hedonic and a utilitarian category whereas trivial attribute is a three-level factor that includes hedonic trivial attributes, utilitarian trivial attributes, and a control group with no trivial attributes.

Please note that while the services are classified as hedonic or utilitarian, the attributes they offer can also be either hedonic or utilitarian independent of the service category. We have added this variable to understand its possible effect. However, we argue that for trivial attributes (and when consumers are aware of this triviality), the type of trivial attribute will not affect the choice likelihood, as they do not create any meaningful differentiation. Therefore, we do not expect to see any effect of the type of the trivial attribute.

In order to decide for service categories and attributes, we first conducted a 45-minute focus group with six undergraduate students. Based on the discussion, we decided to use attending a Graduate Management Admission Test (GMAT) course as utilitarian category and attending a music festival as hedonic category. Using the ideas generated for different attributes during the focus group, we then employed a pre-test with the participation of twenty-three undergraduate students from a public university in the northeast. Participants rated different attributes on a 9-point scale (1: Not at all important, 9: Very important). Since our objective is to see if a trivial attribute will increase the attractiveness of a service provider otherwise in a tie with other ones, we were interested in identifying both important and unimportant attributes with this pretest. Our analyses yielded the following attributes for both of the categories: The important attributes for the GMAT course were 1) number or practice tests given (M: 8.22), 2) availability of private tutoring (M: 6.57), and 3) availability of weeknight classes (M: 7.87). The trivial attributes for GMAT courses were availability of instructors with Ph.Ds. (M: 4.48) and availability of music during class breaks (M: 1.7). Based on our judgment, we identified the former as utilitarian trivial attribute and the latter as hedonic trivial attribute. For music festival category, the important attributes were 1) number of bands (M: 8.3), 2) availability of tents in the festival area for overnight stay (M: 5.61), and 3) the attractiveness of the location of festival area (M: 7.43). The trivial attributes for music festival were availability of free ice (to freshen up) (M: 2.43) and availability of music system from original location where music stems from (e.g. for reggae music, the system would come from Jamaica) (M: 2.57). Based on our judgment, we identified the former as utilitarian trivial attribute and the latter as hedonic trivial attribute. All attributes can be found in Table 1 . 
Table 1. Trivial attributes used in scenarios

\begin{tabular}{lll}
\hline & GMAT & Music Festival \\
\hline Attribute 1 & Number of Practice Tests & Number of Bands \\
Attribute 2 & Availability of Private Tutoring & Availability of Tents for Overnight Stay \\
Attribute 3 & Availability of Weekend Classes & Attractiveness of Location \\
Irrelevant (Hedonic) & Music During Breaks & Free Ice \\
Irrelevant (Utilitarian) & Having a Ph.D. & Instruments from original location \\
\hline
\end{tabular}

In the study, first, participants were given a scenario where they were told to choose between three different service providers. They were told to consider three attributes as important and the three service providers differed on those three attributes in a way that each of the service providers was better than the other two providers at one single attribute. When a service provider was not 'best' on an attribute, it scored equal on that attribute with the other provider who was not 'best' on that specific attribute. By doing this way we aimed to make each service provider equally attractive. In order to control for brand equity, we told subjects that each of the provider had comparable reputation with equal success rates. We also named the providers simply as 'A, B, and C'. Participants were further told that only one institution offered a different attribute but that attribute was trivial and shouldn't matter in their choice. All this information was then presented in a table format.

After seeing the stimuli, participants were asked to indicate their likelihood of choosing each service provider on a 9-point scale (1-very low and 9-very high). They were later asked questions related to manipulation checks and service providers' perceived uncertainty.

\subsubsection{Results}

We first checked the manipulation about the importance of attributes. Our basic argument relies on that subjects do actually find the trivial attributes, trivial. We asked them to answer two different questions as following; the first question was "it is an important attribute to have .....for a GMAT course (Music Festival)" on a 9-point (1: Strongly Disagree - 9: Strongly Agree) scale. The results showed that trivial attributes received the significantly lower rating than the lowest of the rest of the three attributes in the choice set (for GMAT: MTrivial: 4.08 vs. MClosest: $5.92 ; \mathrm{t}=4.12, \mathrm{p}<.01$; and for Music Festival: MTrivial: 4.56 vs. MClosest: $5.98 ; \mathrm{t}=3.6, \mathrm{p}<.01$ ). The second question was "When I decide between institutions for a GMAT course (between music festivals), X is an important factor in my decision" on a 9-point (1: Strongly Disagree - 9: Strongly Agree) scale. The results again showed that trivial attributes received significantly lower rating than the lowest of the rest of the three attributes in the choice set (for GMAT: MTrivial: 4.15 vs. MClosest: 5.97; $\mathrm{t}=4.06, \mathrm{p}<.01$; and for Music Festival: MTrivial: 4.33 vs. MClosest: $5.78 ; \mathrm{t}=3.24, \mathrm{p}<.01$ ). Therefore, our manipulation check about triviality worked. It has to be noted that participants not only accepted the non-importance of the trivial attributes but they also indicated that they do not find them important in their decision-making.

Our second manipulation was about categories and trivial attributes to see whether they were seen as utilitarian and hedonic by the participants as we intended. We used a 6-item scale (3 utilitarian items: worthless / valuable, not useful / useful, not beneficial / beneficial; and 3 hedonic items: unpleasant / pleasant, boring / interesting, annoying / pleasing) separately both for categories and trivial attributes (all 9-point scales) adapted from Batra and Ahtola (1991). The Cronbach alphas for reliability of the scales were .877 at the category level and .895 at the attribute level. Paired samples t-tests confirmed our manipulations though it was marginally significant for Music Festival Category: The means for categories were as follows: GMAT Category: MUtilitarian: 7.85, MHedonic: $4.1 ; \mathrm{t}=10.16, \mathrm{p}<.01$ and Music Festival Category: MUtilitarian: 6.73, MHedonic: $7.76 ; \mathrm{t}=-3.89, \mathrm{p}$ $<.01$. The means for trivial attributes were as follows: GMAT Category - Having a PhD: MUtilitarian: 7.1, MHedonic: $5.62 ; \mathrm{t}=4.23, \mathrm{p}<.01$; GMAT Category -Availability of Music during Class Breaks: MUtilitarian: 3.44, MHedonic: 6.04; $\mathrm{t}=-9.41, \mathrm{p}<.01$; Music Festival Category - Equipment coming from where music was originated: MUtilitarian: 6.64, MHedonic: $5.9 ; \mathrm{t}=1.83, \mathrm{p}<.01$; Music Festival Category -Availability of free ice: MUtilitarian: 4.88, MHedonic: $5.48 ; \mathrm{t}=-1.88, \mathrm{p}<.01$.

We then proceeded to test our hypotheses. Our scenario showed participants 3 institutions (music festivals) that varied in strength on different attributes with one of them offering a trivial attribute (except in the control condition), we then asked participants their choice likelihood of each option separately on a 9-point scale (1: Very Low and 9: Very High). Our design was 3 (Service Providers) X 2 (Category -Utilitarian/Hedonic) X 3 (Trivial Attributes -Hedonic/Utilitarian/Control) with service providers being within subject and other two factors being between subject. A repeated measure ANOVA indicated main effect of Choice Likelihood $(\mathrm{F}=8.32$, $\mathrm{p}<.01$ ) and all other interactions were significant as well (Service Providers*Category: $\mathrm{F}=5.81, \mathrm{p}<.05$; 
Service Providers*Trivial Attributes: $\mathrm{F}=6,584, \mathrm{p}<.01$; and Service Providers*Category*Trivial Attributes: $\mathrm{F}=$ $4.02, \mathrm{p}<.01)$. Therefore, we analyzed each condition separately to understand the effects.

We first looked at the choice likelihoods (of service providers) in the control condition separately for GMAT and Music Festival Categories. In the GMAT category, the effect of Choice Likelihood was not significant $(\mathrm{F}=2,54$, $\mathrm{p}=.137$ ) indicating the different options were seen as equally attractive (MInstitutionA $=4.77$, MInstitutionB $=$ 6.46, and MInstitutionC $=6.3$ ). In the Music Festival Category, the effect of Choice Likelihood was significant $(\mathrm{F}=14.28, \mathrm{p}=.00)$ indicating that one of the options was more attractive than the other option (MFestivalA $=$ 6.87, MFestivalB $=3.8$, and MFestivalC $=3.47$ ). While our manipulation checks indicated the equal attractiveness of the different attributes, participants favored one of the Festivals (that were better on the numbers of bands attribute) more, contrary to our expectations. However, the Festival (A) that participants favored in the control condition is not the Festival that offered the trivial attribute in the treatment condition (Festival C). Therefore, this situation does not compromise our experiment but in fact, it allows us a stronger test of our hypothesis for the treatment condition. If offering a trivial attribute makes the Institution $\mathrm{C}$ among the equally attractive alternatives for GMAT category and reverses the situation for Music Festival category by making Festival $\mathrm{C}$ more attractive, this will prove our hypothesis that offering a trivial attribute will increase the attractiveness of a service firm's offering.

In the treatment conditions where one of the service providers in the choice set offered a trivial attribute, we ran 3 (Service Providers) X 2 (Categories -GMAT/Music Festival) with the former being within subjects and the latter being between subjects. A repeated measure ANOVA indicated a main effect of Choice Likelihood $(\mathrm{F}=$ $18.48, \mathrm{p}<.01)$ but the Category factor didn't interact with the Service Provider $(\mathrm{F}=.18, \mathrm{p}=.84)$. Our H1 indicated that offering a trivial attribute would help a Service Provider in a choice set. Further analysis of pairwise contrasts showed that the choice likelihood of the Service Provider with the trivial attribute was significantly higher than the other two that didn't have trivial attributes in both categories (Means and pairwise contrasts are shown in Table 2). Therefore, H1 was supported (Figure 1).

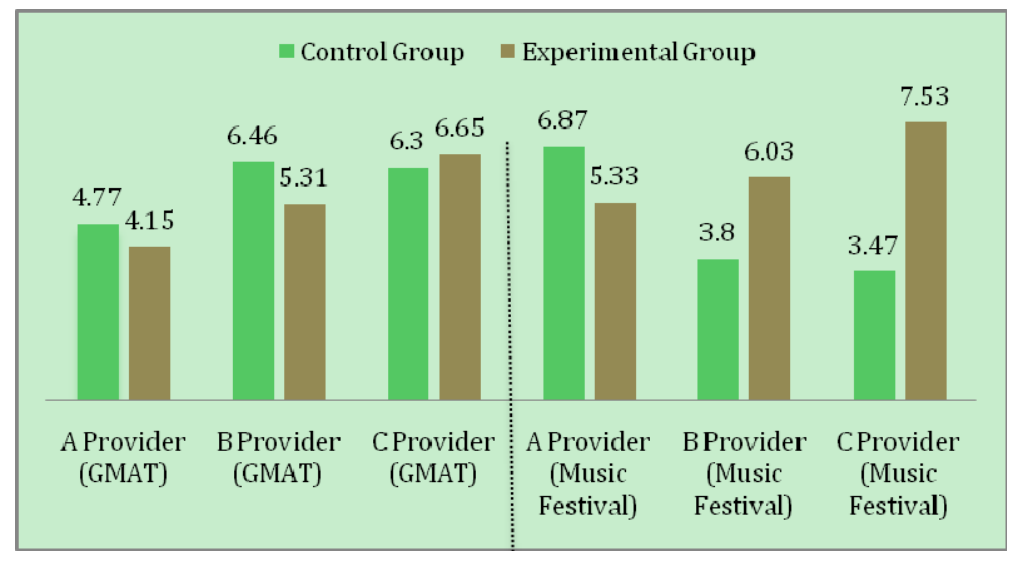

Figure 1. Results of choice likelihoods of providers

Note. a 9-point scale (1-very low and 9-very high).

Our $\mathrm{H} 2$ argued that the effect of trivial attribute would be more pronounced for the Hedonic Service Category (Music Festival) than the Utilitarian Service Category (GMAT course). In order to understand this effect, we created another factor called Treatment with two levels (Trivial and Control). Our design was 2 (Category) X 2 (Treatment) and we ran an ANOVA on the Service Provider C's Choice Likelihood. Please note that we are already shown that offering a trivial attribute increases the choice likelihood from the control group and now we are interested to see if the increase in choice likelihood between control group and treatment group is different for two categories. ANOVA indicated a main effect of Treatment $(\mathrm{F}=30.41, \mathrm{p}<.01)$, main effect of Category ( $\mathrm{F}$ $=6, \mathrm{p}=.02)$, and an interaction effect of Category and Treatment $(\mathrm{F}=21.62, \mathrm{p}<.01)$. The Choice Likelihood increased from 6.3 to 6.6 in Utilitarian (GMAT) category and from 3.5 to 7.5 in Hedonic (Music Festival) Category (Figure 2). Therefore, H2 was supported. 
Table 2. Results of choice analysis

\begin{tabular}{|c|c|c|c|c|c|c|c|c|}
\hline & \multicolumn{4}{|l|}{ GMAT } & \multicolumn{4}{|c|}{ Music Festival } \\
\hline & Provider A & Provider B & & Provider C & Provider A & Provider B & & Provider $C$ \\
\hline $\mathbf{M}_{\text {ChoiceLikelihood }}$ & 4.15 & 5.31 & & 6.65 & 5.33 & 6.03 & & 7.53 \\
\hline \multirow[t]{2}{*}{ Pairwise Contrasts } & $A v s . C$ & $\mathrm{t}=-4.22$ & $p=.00$ & & $A$ vs. $C$ & $\mathrm{t}=-4.41$ & $p=.00$ & \\
\hline & $B v s . C$ & $\mathrm{t}=-2.35$ & $p=.03$ & & $B$ vs. $C$ & $\mathrm{t}=-2.76$ & $p=.01$ & \\
\hline
\end{tabular}

Note. only provider $C$ offers a trivial attribute

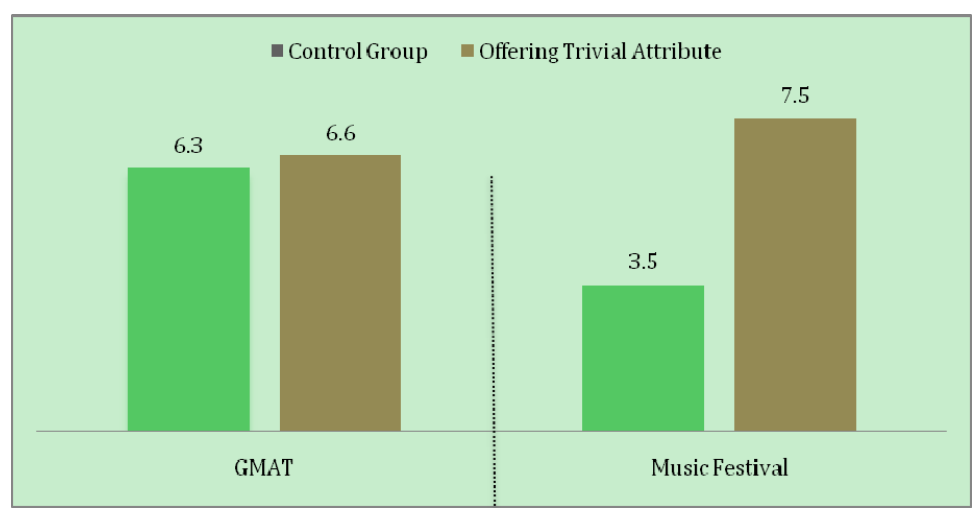

Figure 2. Result of choice likelihood of provider $\mathrm{C}$ with trivial attribute

Note. a 9-point scale (1-very low and 9-very high).

We also tested if the type of trivial attributes (Hedonic vs. Utilitarian) mattered for Service Providers. In order to test this, we ran two separate ANOVAs with the design of 3 (Service Providers) X 2 (Trivial Attributes -Hedonic/Utilitarian) separately for GMAT and Music Festival Categories. While the main effect of Service Provider was significant for both of the categories, as we have already shown before (GMAT: $F=9.06, p<.01$; Music Festival: $F=9.59, \mathrm{p}<.01$ ), the interaction with the Trivial Attributes factor was insignificant for both of the categories (GMAT: $\mathrm{F}=1.14, \mathrm{p}=.32$; Music Festival: $\mathrm{F}=.69, \mathrm{p}=.5$ ). This indicates that while offering a trivial attribute increases the attractiveness of the offer; it does not matter if the trivial attribute is a utilitarian or a hedonic one.

Our results show strong support for all of our hypotheses. In an ambiguous choice situation where at least three service providers have different strengths, the service provider offering a trivial attribute can increase its choice likelihood even after consumers are told about the triviality as it decreases the uncertainty in consumers' minds. This effect is more pronounced when the service is hedonic vs. utilitarian but the type of attribute (hedonic vs. utilitarian) does not matter.

\subsection{Study2: Communication Strategy Using Trivial Attribute Effect}

\subsubsection{Manipulations and Procedure}

A total of seventy-one undergraduate business students participated in exchange of extra credit. We used CD changer as our product category. The subjects were randomly assigned into three groups: First condition was a separate evaluation mode where the first $\mathrm{CD}$ changer concept $(\mathrm{C} 1)$ is explained. This $\mathrm{CD}$ changer concept $(\mathrm{C} 1)$ contained a trivial attribute called "PBS (Package box shape)". The PBS is a trivial attribute because the package box shape creates no value. The second condition was another separate evaluation mode whether the second CD changer concept (C2) is explained. The only difference between the $\mathrm{C} 1$ and $\mathrm{C} 2$ is that the $\mathrm{C} 1$ has trivial attribute while $\mathrm{C} 2$ has not. The third condition was a joint evaluation mode where these two $\mathrm{CD}$ changer concepts $(\mathrm{C} 1$ and $\mathrm{C} 2$ ) were presented and evaluated side by side or jointly.

The dependent variable, willingness to pay (WTP), was measured by an open-ended question. The participants are randomly assigned to into the three groups. The first two groups evaluated the first $\mathrm{CD}$ changer called " $\mathrm{C} 1$ (CD changer with trivial attribute)," and "C2 (CD changer without trivial attribute)" separately. The second group evaluated the two CD changers side by side (See the actual stimulus in the Appendix). 


\subsubsection{Results}

As can be seen in Figure 3, results showed that respondents were willing to pay more money for the $\mathrm{C} 1$ (with trivial attribute) when it was presented and evaluated in the joint evaluation (C1mean: \$68, C2mean: \$40, $\mathrm{t}=6.78, \mathrm{p}<0.01$ ) more than in the separate evaluation (C1mean: $\$ 64, \mathrm{C} 2$ mean: $\$ 49, \mathrm{t}=1.86, \mathrm{p}<0.1$ ). In addition, results from the paired samples t-test showed that the WTP of $\mathrm{C} 1$ was significantly higher in joint evaluation mode (Mean: \$68) than it was in separate evaluation mode $(\$ 64)(t=4.27, \mathrm{p}<0.05)$.

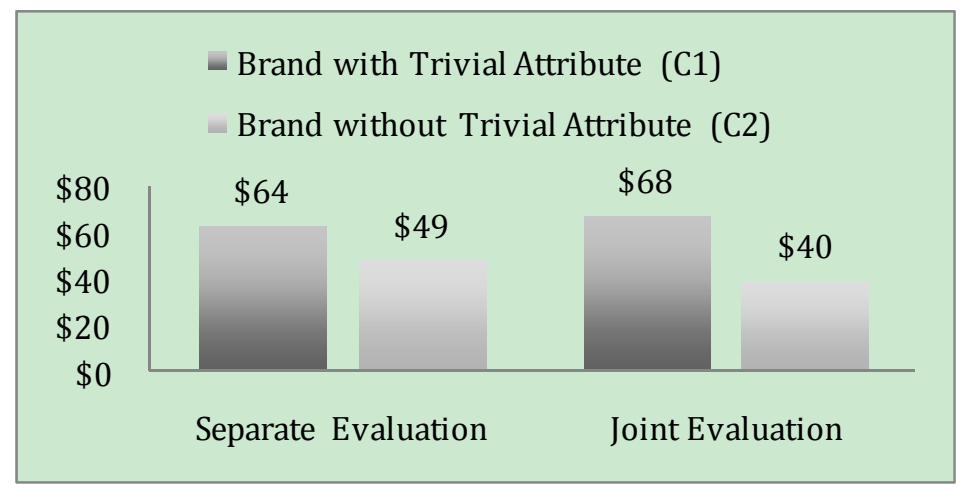

Figure 3. Trivial attribute effect under separate and joint evaluation mode

Note. Willingness to pay (WTP)

\section{Discussion}

Creating brand differentiation has been critical more than ever in our globalized world. Many manufactures of consumer package goods make enormous marketing efforts to differentiate their brands against competitors often by searching and adding new or noble attributes. An important decision to make for marketing managers is to determine what features should be included. In this research, we introduced an unusual brand differentiation strategy using the trivial attribute effect. Results from two experimental studies point out the following; if a trivial attribute as easy to implement as playing music in between class sessions for a GMAT course or distributing free ice at a Music Festival is offered, it can help service providers gain competitive advantage over their competitors. This can allow managers to be more creative and stay competitive in the market. Our results also indicate that this effect is more pronounced in hedonic service categories compared to the utilitarian categories.

From the ethical perspective, offering attributes that don't create meaningful difference for consumers is not deceiving consumers as our results indicate that the effects of trivial attributes hold even after consumers are told about the triviality of them. Moreover, consumers indicated in our study that they are not only aware of the triviality of these attributes but they also think they are not useful in their decision-making. Another result we found that supports the triviality of these attributes is that the type of trivial attribute (hedonic / utilitarian) does not matter. Lastly, in terms of effective marketing communication strategy relying on trivial attribute effect, our results revealed that the joint evaluation mode increases the consumer's willingness to pay more than that of the separate evaluation mode.

\section{Implications and Limitations}

Our research handles both theoretical and practical implications; theoretically it will add to the service literature the applicability of trivial attributes. While research on trivial attributes so far has mainly focused on different consumer goods including down jackets, compact disc players, pasta (Carpenter et al., 1994), coffee, and cologne (Brown \& Carpenter, 2000), we are not aware of any research that has investigated trivial attributes in a service context. In our efforts to understand if using trivial attributes would have a differential effect on hedonic vs. utilitarian services, results suggest that consumers use different types of information evaluating hedonic vs. utilitarian services (Batra \& Ahtola, 1991; Holbrook \& Hirschman, 1982) when trivial attributes are evaluated.

Managerially, it can show the managers a possibly easy way to gain competitive advantage over the competitors. Consider the music festival example above. Using an equipment from the place where the music was originated is not necessarily the best nor the most expensive choice. However, it can possibly give the organizers the edge 
over the competitor festivals if people consider this information positively in their decision-making. Lastly, from the perspective of marketing communication strategy, attributes themselves can also be either utilitarian or hedonic and it will be up to the marketers to choose the type of the trivial attributes for their offerings. However, this becomes important only if this choice affects the consumer response to the offering and helps the marketers to differentiate their offering particularly using the joint evaluation mode.

In services, one of the main reasons why it is difficult to create and maintain advantage is the fact that in services, competitors can easily copy the aspects of successful offerings (Storey \& Easingwood, 1998). This then puts pressure on service managers to stay competitive in the market place. Our research findings contribute to the service sector. Service sector compromises $68 \%$ of US GDP and $80 \%$ of the US jobs (Office of the US Trade Representative) and this distribution is similar in all developed countries as there is a positive correlation between GDP and the share of the service sector in an economy (Sherom \& Saubbotina, 2000). While the service sector has such an important share in the economy, at the same time, service management is different from managing goods (Mittal, 1999; Parasuraman, Zeithaml, \& Berry, 1985) and it is more difficult (Storey\&Easingwood, 1998). Moreover, the consumer behavior for services is also different than it is for goods and it is more difficult for consumers to make a choice along the alternatives (Gabott \& Hogg, 1994). In sum, all these factors about services make it an important domain to understand if companies can use trivial attributes to gain advantage in the marketplace and our research sheds light to managers in the service sector.

Our research has several limitations. First of all, it is a challenge to define triviality in a service context. Our manipulation checks showed that we were successful but future research should use different approaches for this manipulation. Moreover, we only investigated within a student population, in categories where student knowledge is high. Future research should investigate the phenomena with non-student participants and vary the knowledge of the category within them. Also, our categorization of services (utilitarian vs. hedonic) is not the only way one can look at the issue and future research should investigate different features of service industry such as separable vs. inseparable services. Lastly, while our research clearly indicates the effect of trivial attributes, it does not offer any process mechanisms as to how it actually works in consumer minds. Future research should investigate this issue deeper. For example, our finding that participants didn't think the trivial attribute was important for decision making is especially interesting considering that it was used by them, as their choice likelihood scores indicated. Another interesting way to look at these phenomena is that why this effect is more pronounced for hedonic categories compared to the utilitarian categories. While our argument is about the anxiety provoking nature of utilitarian services, another alternative explanation (though in the same direction) exists. Consumers' involvement with the product category will affect how much information they process. Therefore, in the service categories where involvement is more, the effect of trivial attributes might be more pronounced. Shavitt (1992) finds that involvement will be higher with the hedonic services than with the utilitarian services implying that the effect of trivial attributes will be more pronounced with the hedonic categories. Future research can look at these alternative explanations to investigate the process mechanisms for why trivial attributes help hedonic services more.

\section{Acknowledgment}

This article benefited from partial fund by Michigan Tech University's REF (Research Excellent Fund).

\section{References}

Albrecht, C. M., Neumann, M. M., Haber, T. E., \& Bauer, H. H. (2011). The relevance of irrelevance in brand communication. Psychology \& Marketing, 28(1), 1-28. http://dx.doi.org/10.1002/mar.20378

Babin, B. J., Darden, W. R., \& Griffin, M. (1994). Work and/or fun: measuring hedonic and utilitarian shopping value. Journal of Consumer Research, 644-656. http://dx.doi.org/10.1086/209376

Batra, R., \& Ahtola, O. T. (1991). Measuring the hedonic and utilitarian sources of consumer attitudes. Marketing Letters, 2(2), 159-170. http://dx.doi.org/10.1007/BF00436035

Botti, S., \& McGill, A. L. (2011). The locus of choice: Personal causality and satisfaction with hedonic and utilitarian decisions. Journal of Consumer Research, 37(6), 1065-1078. http://dx.doi.org/10.1086/656570

Broniarczyk, S. M., \& Gershoff, A. D. (2003). The reciprocal effects of brand equity and trivial attributes. Journal of Marketing Research, 40(2), 161-175. http://dx.doi.org/10.1509/jmkr.40.2.161.19222

Brown, C. L., \& Carpenter, G. S. (2000). Why is the trivial important? A reasons-based account for the effects of trivial attributes on choice. Journal of Consumer Research, 26(4), 372-385. http://dx.doi.org/10.1086/209569 
Carpenter, G. S., Glazer, R., \& Nakamoto, K. (1994). Meaningful brands from meaningless differentiation: The dependence on irrelevant attributes. Journal of Marketing Research, 339-350. http://dx.doi.org/10.2307/3152221

Chatterjee, S., Heath, T. B., \& Min, J. (2009). The susceptibility of mental accounting principles to evaluation mode effects. Journal of Behavioral Decision Making, 22(2), 120-137. http://dx.doi.org/10.1002/bdm.616

Cooke, A. D., Janiszewski, C., Cunha Jr, M., Nasco, S. A., \& De Wilde, E. (2004). Stimulus context and the formation of consumer ideals. Journal of Consumer Research, 31(1), 112-124. http://dx.doi.org/10.1086/383428

Devlin, J. F. (1998). Adding value to service offerings: the case of UK retail financial services. European Journal of Marketing, 32(11/12), 1091-1109. http://dx.doi.org/10.1108/03090569810243730

Dhar, R., \& Sherman, S. J. (1996). The effect of common and unique features in consumer choice. Journal of Consumer Research, 193-203. http://dx.doi.org/10.1086/209477

Dhar, R., Nowlis, S. M., \& Sherman, S. J. (1999). Comparison effects on preference construction. Journal of Consumer Research, 26(3), 293-306. http://dx.doi.org/10.1086/209564

Gabbott, M., \& Hogg, G. (1994). Consumer behaviour and services: a review. Journal of Marketing Management, 10(4), 311-324. http://dx.doi.org/10.1080/0267257X.1994.9964277

Holbrook, M. B., \& Hirschman, E. C. (1982). The experiential aspects of consumption: consumer fantasies, feelings, and fun. Journal of Consumer Research, 132-140. http://dx.doi.org/10.1086/208906

Hsee, C. K., \& Leclerc, F. (1998). Will products look more attractive when presented separately or together?. Journal of Consumer Research, 25(2), 175-186. http://dx.doi.org/10.1086/209534

Hsee, C. K., Loewenstein, G. F., Blount, S., \& Bazerman, M. H. (1999). Preference reversals between joint and separate evaluations of options: A review and theoretical analysis. Psychological Bulletin, 125(5), 576. http://dx.doi.org/10.1037/0033-2909.125.5.576

Lazarus, R. S. (1991). Progress on a cognitive-motivational-relational theory of emotion.American Psychologist, $46(8), 819$.

Miljkovic, D., Gong, J., \& Lehrke, L. (2009). The Effects of Trivial Attributes on Choice of Food Products. Agricultural \& Resource Economics Review, 38(2), 142.

Mittal, B. (1999). The advertising of services meeting the challenge of intangibility.Journal of Service Research, 2(1), 98-116. http://dx.doi.org/10.1177/109467059921008

Parasuraman, A., Zeithaml, V. A., \& Berry, L. L. (1985). A conceptual model of service quality and its implications for future research. Journal of Marketing, 41-50. http://dx.doi.org/10.2307/1251430

Porter, M. E. (1985).Competitive Advantage. The Free Press, A Division of MacMillan, Inc., New York.

Rust, R. T., \& Chung, T. S. (2006).Marketing models of service and relationships. Marketing Science, 25(6), 560-580. http://dx.doi.org/10.1287/mksc.1050.0139

Schilling, M. A., \& Hill, C. W. (1998). Managing the new product development process: strategic imperatives. The Academy of Management Executive, 12(3), 67-81.

Shafir, E., Simonson, I., \&Tversky, A. (1993). Reason-based choice. Cognition, 49(1), 11-36. http://dx.doi.org/10.1016/0010-0277(93)90034-S

Shavitt, S. (1992). Evidence for predicting the effectiveness of value-expressive versus utilitarian appeals: a reply to Johar and Sirgy. Journal of Advertising, 21(2), 47-51. http://dx.doi.org/10.1080/00913367.1992.10673367

Sheram, K., \& Soubbotina, T. P. (2000). Beyond economic growth: Meeting the challenges of global development. IBRD/World Bank.

Storey, C., \& Easingwood, C. J. (1998). The augmented service offering: a conceptualization and study of its impact on new service success. Journal of Product Innovation Management, 15(4), 335-351. http://dx.doi.org/10.1111/1540-5885.1540335

Strahilevitz, M., \& Myers, J. G. (1998). Donations to charity as purchase incentives: How well they work may depend on what you are trying to sell. Journal of Consumer Research, 24(4), 434-446. http://dx.doi.org/10.1086/209519 
Xiao, N., Dacin, P., \& Ashworth, L. (2010). Conditions Under Which "Trivial" Attributes Become Important in Consumer Judgment. In M. C. Campbell, J. Inman, R. Pieters, \& M. N. Duluth (Eds.), NA - Advances in Consumer Research (pp. 934-935). Association for Consumer Research.

\section{Appendix A}

\section{Stimulus Used for the Separate and Joint Evaluation Mode}

Stimulus used in the separate evaluation.

Imagine that a national brand of manufactures offers a friend of yours opportunity to participate in a " $\mathrm{CD}$ changer evaluation" program. According to this program, after your friend purchases ten items from this manufacturer, your friend will obtain one of CD changers below. However, your friend is not interested in a CD changer, and therefore, tells you that if your friend earns the reward, s/he will give it to you. But, to transfer the reward to you, you are required to answer the question below.

[CD Changer Concept (C1) with trivial attribute]

Note that one of features of the CD changer is PBS which is an index of package box shape. The smaller the PBS, the more it is round. Please indicate what price you would be willing to pay for the CD changers below?

\begin{tabular}{|l|l|l|}
\hline & CD capacity & PBS \\
\hline CD Changer Concept 1 & It can hold 5 CDs & 0.003 \\
\hline
\end{tabular}

How much would you be willing to pay for the CD changer Concept1 (\$

)

[CD Changer Concept (C2) without trivial attribute]

Note that one of features of the CD changer is PBS which is an index of package box shape. The smaller the PBS, the more it is round. Please indicate what price you would be willing to pay for the CD changers below?

\begin{tabular}{|l|l|l|}
\hline & CD capacity & PBS \\
\hline CD Changer Concept 2 & It can hold 20 CDs & None \\
\hline
\end{tabular}

How much would you be willing to pay for the CD changer Concept2 (\$

)

Stimulus used in the joint evaluation.

\begin{tabular}{|l|l|l|}
\hline & CD capacity & PBS \\
\hline CD Changer Concept1 & It can hold 5 CDs & 0.003 \\
\hline CD Changer Concept2 & It can hold 20 CDs & None \\
\hline
\end{tabular}

How much would you be willing to pay for the CD changer Concept1 $(\$$

How much would you be willing to pay for the CD changer Concept2 (\$

\section{Copyrights}

Copyright for this article is retained by the author(s), with first publication rights granted to the journal.

This is an open-access article distributed under the terms and conditions of the Creative Commons Attribution license (http://creativecommons.org/licenses/by/3.0/). 